\title{
Klippel-Trenaunay Syndrome
}

\author{
R. S. Naik
}

Received: 13 September 2004 / Accepted: 11 August 2007

A 6-year-old male child was presented with large varicosities of superficial veins on the lateral aspect of right lower limb. The patient could walk only with crutches, as the foot of the affected limb, with dilated tortuous veins, was too painful to carry the body weight. The principal enlarged serpentine vein was almost of the thickness of the distended small bowel loop, non-pulsatile and compressible following elevation of the right leg. Transmitted pulsation could be elicited due to long column of blood. There were apparent lengthening of the right lower limb by $3.5 \mathrm{~cm}$, and hypertrophy of the affected limb at thigh, calf and foot level. No other obvious deformities or lymphoedema were found on the body. A diagnosis of Klippel-Trenaunay Syndrome was made.

Klippel-Trenaunay Syndrome (KTS) was initially described in 1900 as with a triad consisting of port-wine stain varicosities and hypertrophy of soft tissue and bone. Majority of patient present with the typical triad [1], but a small proportion may have an atypical or incomplete presentation [2], as in this particular case, which did not show port-wine stain. KTS is a rare, non-familial, congenital venous malformation seen in the childhood and it affects one or more limbs, usually a lower one [3], and in an unusual site [4], i.e. the lateral aspect of thigh (Fig.1). Varicosities may be extensive and may be associated with deep vein anomalies including aneurysmal dilatation, hypoplasia, aplasia and absent or incomplete valves. The varicosities may or may not be associated with lymphatic anomalies. Limb length discrepancy may be present, which was obvious in the present case. Absence of thrill, nonpulsatile cutaneous veins, lymphoedema and other arteriovenous malformations rule out Park-Weber Syndrome. Evaluation of the deep venous system can be completed

\section{R. S. Naik}

Naik Nursing Home,

Arya Nagar, Durg (C.G.) - 491001

mantosh2@rediffmail.com

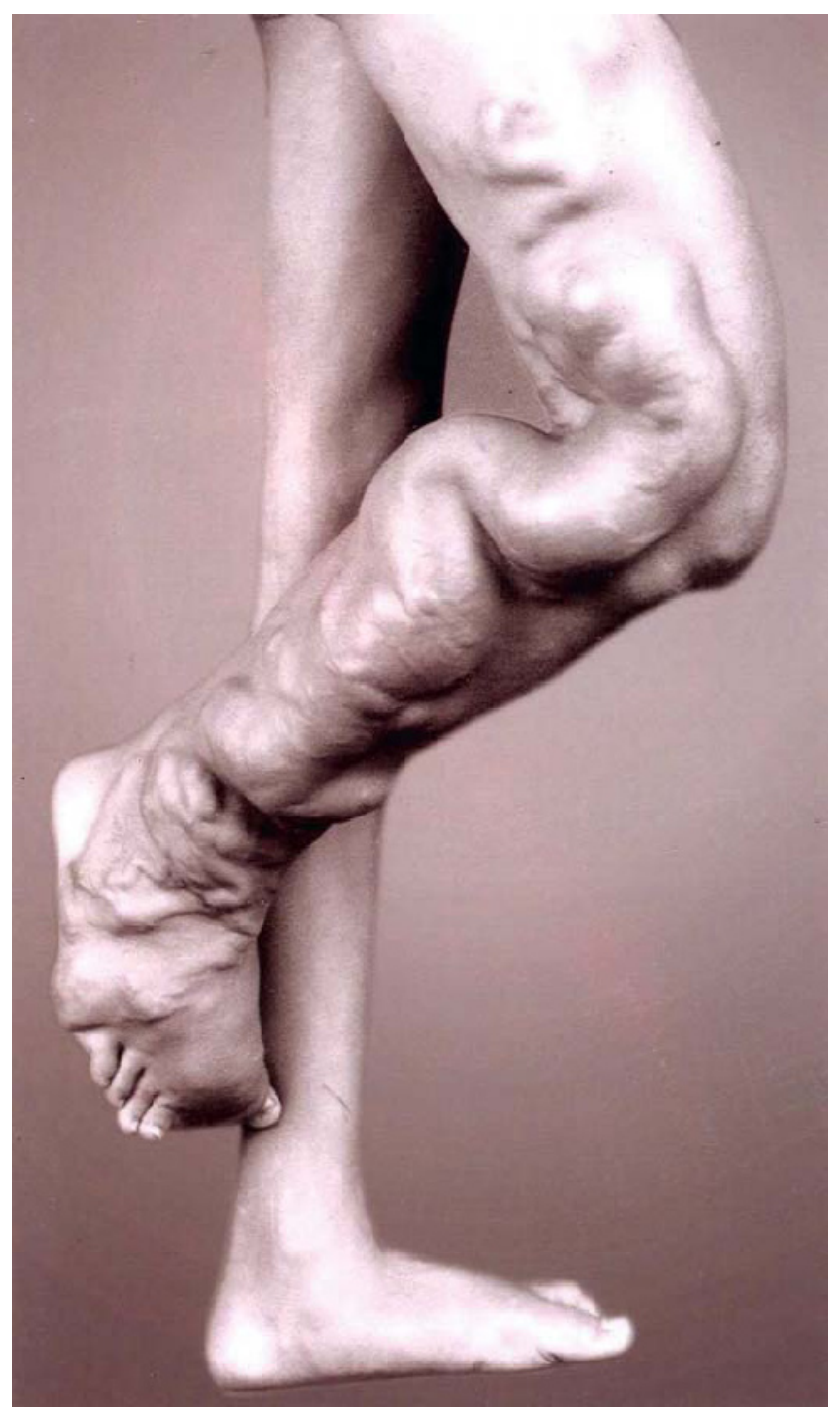

Fig. 1 Limb length discrepancy and large varicosity on the lateral aspect of right lower limb. 
with duplex scanning, contrast venography, ultrasonography, MRI in imaging soft tissue and arteriography for A.V. fistula.

This atypical and rare case of KTS is presented precisely to acquaint and sensitize the surgeons towards the diagnostic and therapeutic challenges it poses. The treatment is essentially the elevation of limb and the use of compressible stockings. Before surgical intervention it is imperative to ascertain the presence of deep veins and at the same time duly weigh and consider the potential risk and benefits. It is further emphasized that surgery has limited use in the management of KTS.

\section{References}

1 Schwartz Seymour I et al (1998) Principles of Surgery, $7^{\text {th }}$ ed McGraw-Hill Co Inc.

2 Fishman SJ, Mulliken JB (1993) Hemangiomas and vascular malformations of infancy and childhood. Pediatr Clin North Am 40(6):1177-1200

3 Hai AA, Shrivastava RB (2003) The Association of Surgeons of India : Text Book of Surgery, 1st ed, Tata McGraw-Hill Co Pvt Ltd

4 Samuel M, Spitz L (1995) Klippel-Trenaunay syndrome; Clinical features, complications and Management in Children Br J Surg 82:757-761 